\title{
A numerical study on the impact of nonlinear interactions on the amplitude of the migrating semidiurnal tide
}

\author{
C. M. Huang ${ }^{1,2}$, S. D. Zhang ${ }^{1,2}$, and F. Yi ${ }^{1,2}$ \\ ${ }^{1}$ School of Electronic Information, Wuhan University, Wuhan, HUBEI 430079, People's Republic of China \\ ${ }^{2}$ Laboratory of Geospace Environment and Geodesy, Wuhan University, Wuhan, HUBEI 430079, People's Republic of China
}

Received: 15 June 2006 - Revised: 11 September 2006 - Accepted: 24 November 2006 - Published: 21 December 2006

\begin{abstract}
To quantitatively study the effects of nonlinear interactions on tide structure, a nonlinear numerical tidal model is developed, and the reliability and convergence of the adopted algorithm and coding are checked by numerical experiments. Under the same conditions as those employed by the GSWM-00 (Global Scale Wave Model 2000), our model provides the nonlinear quasi-steady solution of the migrating semidiurnal tide, which differs from the GSWM00 result (the linear steady solution) in the MLT region, especially above $100 \mathrm{~km}$. Additionally, their amplitude difference displays a remarkable month-to-month variation, and its significant magnitudes occur during the month with strong semidiurnal tide. A quantitative analysis suggests that the main cause for the amplitude difference is that the initial migrating 12-h tide will interact with the mean flow as well as the nonlinearity-excited 6-h tide, and subsequently yield a new 12-h tidal part. Furthermore, our simulations also show that the mean flow/tidal interaction will significantly alter the background wind and temperature fields. The large magnitudes of the tidal amplitude difference and the background alteration indicate that the nonlinear processes involved in tidal propagations should be comprehensively considered in the description of global atmospheric dynamics in the MLT region. The comparisons among our simulations, the GSWMs and some observations of tides suggest that the nonlinearityinduced tidal structure variation could be a possible mechanism to account for some discrepancies between the GSWMs and the observations.
\end{abstract}

Keywords. Meteorology and atmospheric dynamics (General circulation; Middle atmosphere dynamics; Waves and tides)

\section{Introduction}

Atmospheric solar tides (hereinafter tides) are global-scale waves with periods which are the harmonics of a solar day.

Correspondence to: S. D. Zhang

(zsd@whu.edu.cn)
Tides are usually generated by thermal heating (through processes such as the absorption of solar radiation) in the tropical troposphere and stratosphere. They can freely propagate up and away from their source region, and transport energy and momentum to upper altitudes, leading to the coupling between the lower atmosphere and the middle and upper atmosphere. Due to an exponential decrease in atmospheric density, tides have large horizontal wind amplitudes (several tens of $\mathrm{ms}^{-1}$ ) and become one of the most striking features in the mesosphere and lower thermosphere (MLT) (Vincent et al., 1989; Morton et al., 1993; Hays et al., 1994; McLandress et al., 1994). They are believed to play an important role in the large-scale circulation patterns and strongly modulate the propagation conditions experienced by upward propagating gravity waves in the MLT. Besides the dynamics, tides can also significantly influence the chemistry of the MLT region (Forbes et al., 1993; Smith, 2004). By definition, the migrating tides are a subset of tides propagating westward with the apparent motion of the Sun, with zonal wave number $s$ equal to the frequency $n$ in cycles per day. The migrating tidal component with a frequency $n=2$ is named the migrating semidiurnal tide, which is one of the most prominent tidal components found in the MLT.

The seasonal and geographic characteristics of tides have been experimentally studied over the last three decades with measurements of both satellite (Hays et al., 1994; McLandress et al., 1994; Burrage et al., 1995; Khattatov et al., 1996; McLandress et al., 1996; Palo et al., 1997; Bruinsma et al., 2002; Manson et al., 2002a; Shepherd and FrickeBegemann, 2004) and ground-based instruments, including MF radars (Khattatov et al., 1996; Palo et al., 1997; Vincent et al., 1998; Pancheva et al., 2002; Namboothiri et al., 2004; Zhang et al., 2004; Riggin et al., 2003), VHF radars (Yi, 2001), Meteor radars (Pancheva et al., 2002; Batista et al., 2004), Lidars (Williams and She, 1998; States and Gardner, 2000; Kumar et al., 2003; She et al., 2003; Shepherd and Fricke-Begemann, 2004) and Incoherent-Scatter radars (Palo et al., 1997). Although global ground-based observational campaigns (Pancheva et al., 2002; Palo et al., 1997; Manson et al., 1999; 2002b; 2004) and satellite observations have

Published by Copernicus GmbH on behalf of the European Geosciences Union. 
significantly increased the amount of data available for tidal analysis on a planetary scale in the past few years, the observations are still not capable of providing a fully global, continuous characterization of tides, due to their limited spatial and temporal coverage (e.g. the satellite observations have poor local time coverage, whereas the ground-based observational instruments have some irregularity in latitudinal and longitudinal coverage). Since modeling work can be a helpful supplement to observations, many efforts have been undertaken to develop tidal numerical models.

Atmospheric tides have been studied extensively with linear models for more than 30 years. Since the development of classical tidal theory in Chapman and Lindzen (1970), increasing complexities were systematically introduced to 2-D linearized, steady-state numerical models as in Forbes (1982), Vial (1986), Hagan et al. (1995, 1999, 2001), Hagan and Forbes (2002, 2003), and Wood and Andrews (1997), to take into account the zonal-mean zonal wind and temperature as a function of latitude and height, thermotidal heating, and dissipation processes. The GSWMs, i.e. GSWM-95 (Hagan et al., 1995) and the sequential updated versions GSWM-98 (Hagan et al., 1999), GSWM-00 (Hagan et al., 2001) and GSWM-02 (Hagan and Forbes, 2002, 2003), are the most widely accepted numerical tidal models. These models have been quite successful in reproducing some observed features of the vertical, latitudinal and seasonal structures of atmospheric tides.

Although in the later versions of GSWMs, the impact of the gravity wave breaking on tides is parameterized, the serial GSWMs are essentially 2-dimensional, linearized, steadystate numerical tidal and planetary wave models, which extend from the ground to the thermosphere. It is well known that in the MLT, large tidal amplitude may lead to many nonlinear effects, which cannot be described appropriately by the linearized GSWMs. In fact, a number of tidal observations in different latitudinal regions (Burrage et al., 1995; Palo et al., 1997; Oberheide et al., 2000; Bruinsma et al., 2002; Grieger et al., 2002; Pancheva et al., 2002; She et al., 2003; Batista et al., 2004; Zhang et al., 2004) showed obvious discrepancies from the GSWMs, especially at altitudes above $90 \mathrm{~km}$, where larger tidal amplitudes appear and have the potential to lead to a stronger nonlinear interaction. The effect of the nonlinear interaction is not clear and needs to be investigated.

As for nonlinear tidal models, some tidal investigations with General Circulation Models (GCMs) (e.g. Fesen et al., 1993; Miyahara et al., 1993; Miyahara and Miyoshi, 1997; Grieger et al., 2002) have provided important insights into wave-tide and tide-mean flow interactions, which are unresolved in a linear tidal theory. Moreover, some excellent work on the nonlinear calculation of the semidiurnal migrating tide has been done by Angelats i Coll and Forbes (2002). They reveal that the nonmigrating semidiurnal tides in the MLT can be generated by nonlinear wave-wave interaction and provide a distinct physical explanation. In particular, their work demonstrates the zonal mean zonal winds driven by dissipation of the semidiurnal tide and verifies the importance of tides on the thermospheric mean circulation, in accordance with the work by Miyahara and Wu (1989) and Miyahara et al. (1991).

For exploring the impact of nonlinear interactions on tidal structure, we developed a nonlinear numerical tidal model, and presented comparisons between the nonlinear propagation solutions from this model and the linear steady-state solutions from the GSWM-00. For the convenience of comparison, here we try to keep all the calculation conditions (including the prescribed background, the polar boundaries, etc.) consistent with the GSWM-00, except that the nonlinear terms are retained in order to ensure that the differences between them mainly come from nonlinearity. Initialized by the GSWM-00 results, our nonlinear tidal model can present tidal propagation solutions while the GSWM-00 provides steady-state tidal solutions. Therefore, for the convenience of comparison with the GSWM-00, we obtain the tidal amplitudes by using a cosine function to fit the propagation solutions (detailed illustration can be found in Sect. 2.4)

The paper is organized as follows. In Sect. 2, our numerical tidal models, mainly including governing equations, initial values, boundary conditions and processing algorithm, are introduced in detail. In addition, the model examination by comparing our linear model results and the GSWM- 00 is carried out. Section 3 gives the nonlinear simulation results. The numerical convergence of our linear and nonlinear tidal models is verified by simulations starting from zero tidal oscillations in the next section. Sections 5 and 6 are, respectively, devoted to discussions and conclusions. The technical details of our numerical algorithm can be found in the Appendix.

\section{Numerical models}

\subsection{Governing equations}

Our nonlinear tidal model is similar to the GSWM-00, but with that the linear assumption, namely tidal fields are considered as small perturbations on a basic state, and the hydrostatic assumption are removed. Other basic assumptions of the GSWM-00 are retained: the Earth is assumed to be a smooth sphere and the atmosphere is assumed to be a compressible, shallow perfect gas; tidal fields are treated as perturbations on the initial given basic state that is a purely zonal flow dependent only on latitude and altitude, and the zonal mean meridional and vertical winds are neglected. Therefore, the Navier Stokes equations can be written as below: 


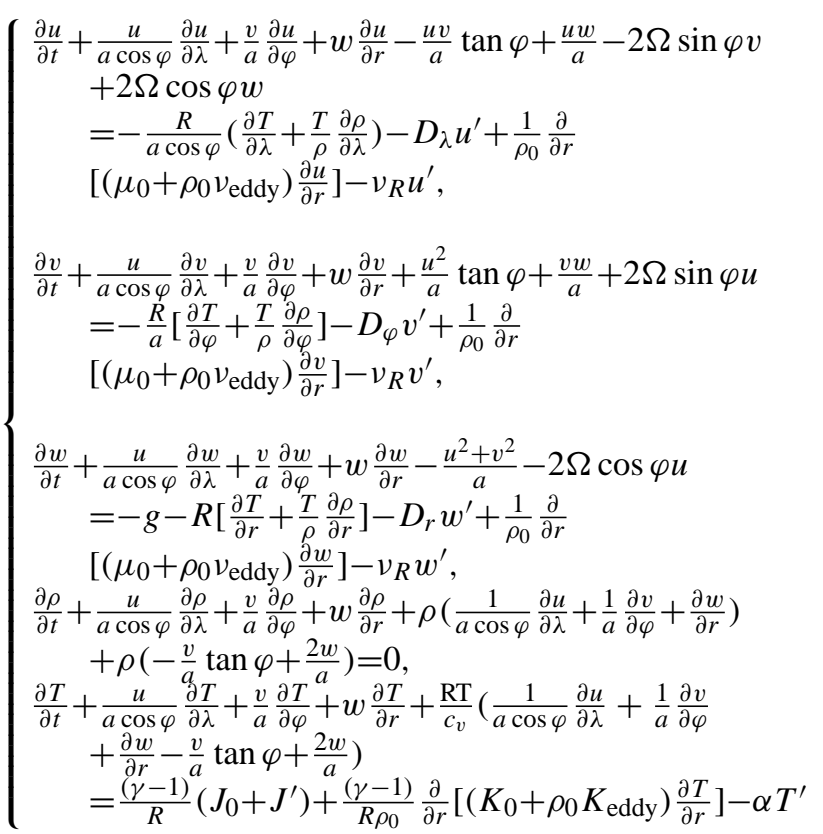

where $t$ is local time; $\quad r(6371 \mathrm{~km} \leq r \leq 6507 \mathrm{~km}), \quad \lambda$ $\left(0^{\circ} \leq \lambda \leq 360^{\circ}\right)$ and $\varphi\left(-90^{\circ} \leq \varphi \leq 90^{\circ}\right)$ are vertical (positive upward), zonal (positive eastward) and meridional (positive northward) coordinates, respectively; $u, v, w$ are the eastward, northward and vertical velocities, respectively; $\rho, T$ are the density and temperature; $u^{\prime}, v^{\prime}, w^{\prime}$ are the perturbation eastward, northward and vertical velocities, respectively; $T^{\prime}$ are the perturbation temperature; $u_{0}, \rho_{0}, T_{0}$ are the zonal mean wind, background density and temperature, respectively; $R=286.9821 \mathrm{~N} \cdot \mathrm{m} / \mathrm{kg} \cdot \mathrm{K}$ is the gas constant; $c_{v}=718 \mathrm{~J} / \mathrm{kg} \cdot \mathrm{K}$ is the heat capacity at constant volume; $c_{p}=c_{v}+R$ is the heat capacity at constant pressure; $\gamma=c_{p} / c_{v} ; \Omega=7.292 \times 10^{-5} \mathrm{Rads}^{-1}$ is the Earth's rotation rate; $a=6371 \mathrm{~km}$ is the mean Earth radius; $\alpha$ is the Newtonian cooling coefficient; $D_{\lambda}, D_{\varphi}, D_{r}$ are the ion drag forces in zonal, meridional, and vertical directions, respectively; $v_{R}$ is the coefficient of Rayleigh friction; $J_{0}+J^{\prime}$ is the net heat input per unit mass; $J^{\prime}$ is the thermotidal heating; $K_{0}$ is the molecular thermal conductivity coefficient $\left(K_{0}=0.015 T_{0}^{2 / 3} / M\right.$, where $M$ is the mean molecular weight), $\mu_{0}$ is the dynamic molecular viscosity coefficient $\left(\mu_{0}=0.266 K_{0} / R\right), \nu_{\text {eddy }}$ is the kinematic eddy viscosity coefficient, $K_{\text {eddy }}$ is the eddy thermal conductivity coefficient $\left(K_{\text {eddy }}=1.36 v_{\text {eddy }}\right)$.

Evidently, in Eqs. (1), the linear assumption is not adopted and all the nonlinear terms are retained. Therefore, we call the Eqs. (1) nonlinear formulations. By inputting the initial values, we can obtain the time-dependent solutions of Eqs. (1), which can be called tidal nonlinear propagation solutions. Since we focus on the migrating semidiurnal tidal solution in this paper, in our models the semidiurnal tide heating is the same as that adopted by the GSWM-00 and the diurnal heating source is turned off. If the semidiurnal tide is the only disturbance included in the initial values, the nonlinear model can offer the possibility to quantitatively study the effects of the nonlinear interactions among the semidiurnal tide, the mean flow and the nonlinearity-excited waves on the tides and mean flow, while other nonlinear processes involved in tidal propagation, such as the resonant interaction between the diurnal and semidiurnal tides (which is beyond the purpose of this paper) are excluded.

Reviewing the GSWM-00, Hagan et al. (2001) adopted the linear assumption, so the quadratic and higher order terms in Eqs. (1) are neglected and the linearized forms are as below:

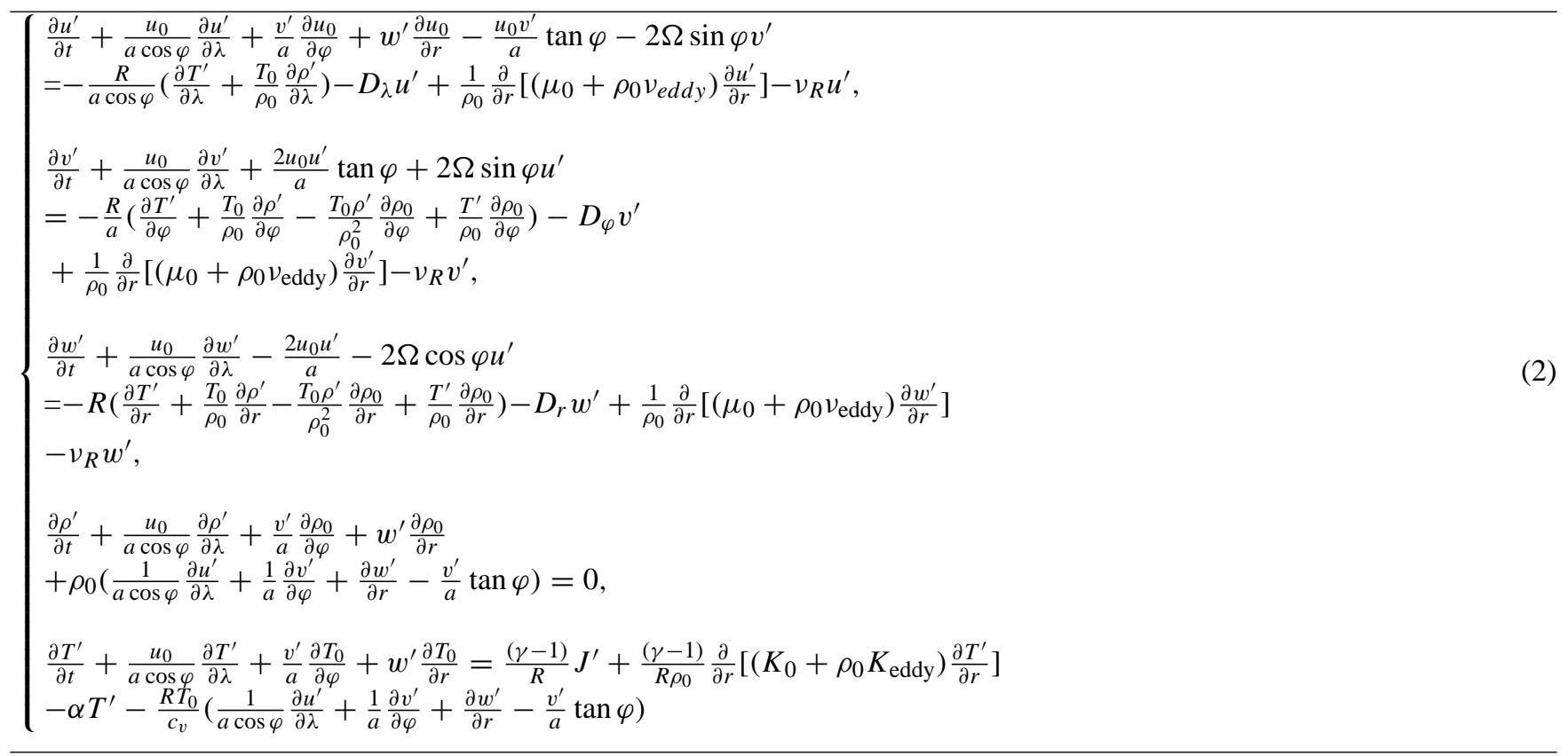


In Eqs. (1) and (2), the thermotidal heating $J^{\prime}$, Newtonian cooling efficient $\alpha$, ion drag forces $\left(D_{\lambda}, D_{\varphi}\right.$ and $\left.D_{r}\right)$, kinematic eddy viscosity coefficient $\nu_{\text {eddy }}$, and efficient of Rayleigh friction $v_{R}$ are all same as those specified in GSWM-00. In GSWM-00, the time-dependent factor $e^{i n(\Omega t+\lambda)}(n=2$ for the semidiurnal component) is left out from both sides of the Eqs. (2), so that the GSWM-00 results are the time-independent (steady-state) solutions. It is well known that the GSWM-00 results are essentially the latitudeheight distributions of tidal amplitudes and phases in each month of the year.

Based on Eqs. (1) and (2), our nonlinear and linear tidal models are numerically resolved by the completely identical temporal integration and spatial difference methods. A detailed description of the spatial difference equations and computational methods, temporal integration method and the specification of the time step length can be found in the Appendix. By inputing the initial values, we can obtain the time-dependent nonlinear and linear propagation solutions of tides. They are then processed by the same method to obtain the background and tidal components. Since the nonlinear model is same as the linear one but with the nonlinear terms switched on, the differences between the nonlinear and linear simulations can reflect the impact of the nonlinear processes on the tidal structure. We note here that our linear propagation solutions and the GSWM-00 results are deduced from the same equations (i.e. Eqs. 2); after dropping the timedependant factor $e^{i n(\Omega t+\lambda)}$ from the former, they should be equal. If the GSWM-00 results are inputted as the initial values, our linear model should retain the initial tidal structures unchanged.

\subsection{Initial values}

Because GSWM-00 can provide an increasingly reasonable estimate of most migrating tidal characteristics in the MLT region, and its calculation results are available from the NCAR CEDAR database (http://www.hao.ucar.edu/public/ research/tiso/gswm/gswm.html), we choose the GSWM-00 results as the initial tidal disturbances of our models (both linear and nonlinear models). Taking the real parts of the steady-state solutions of the migrating semidiurnal tide with respect to $t=0$ in a certain month as the initial disturbances of Eqs. (1) and (2), the nonlinear and linear propagation solutions of the semidiurnal tide can be calculated.

\subsection{Boundary conditions}

A periodic boundary is implied in the zonal direction. For the convenience of comparison with the GSWM-00, the disturbance winds, temperature and density are set to zero at the geographic poles to keep consistent with the GSWM-00. At the lower boundary $(z=0)$, the conditions utilized by the GSWM-00 are adopted, while at the upper boundary, in order to avoid the influence of the wave reflection on the in- terior solutions, a projected characteristic line boundary is adopted, which consists of the compatibility equations along the outgoing projected characteristic lines and the projected characteristic quantity conservation equations along the incoming projected characteristic lines, described in detail by Zhang and Yi (1999). This boundary specification has been successfully applied to simulate the nonlinear propagation of atmospheric waves in the Cartesian and spherical coordinates (Zhang and Yi, 1999, 2004), and proved to be effective in preventing the wave reflection from the upper boundary. In this study, the top boundary is set at $136 \mathrm{~km}$. Our numerical experiments have verified that this projected characteristic line boundary hardly impacts the solution in the inner computational region, especially below $110 \mathrm{~km}$. This boundary makes our calculation height range much smaller than that in the GSWM-00 (the top boundary is set at $\sim 250 \mathrm{~km}$ ).

\subsection{Processing algorithm}

In order to obtain the mean flow and tidal components, a cosine function is used to fit the computational results $\left(f_{c}(\lambda, \varphi, r, t)\right)$ based on the variable $\lambda$, that is:

$f_{c}(\lambda, \varphi, r, t)=f_{0}(\varphi, r, t)+f_{1}(\varphi, r, t) \cos \left[2(\Omega t+\lambda)+f_{2}(\varphi, r, t)\right]$,

where $f_{0}(\varphi, r, t)$ is the mean flow (mean flow alteration) for the nonlinear (linear) model; $\boldsymbol{f}_{1}(\varphi, r, t)$ and $\boldsymbol{f}_{2}(\varphi, r, t)$ are tidal amplitude and phase, respectively.

We would like to emphasize here, that all the results presented in this paper are the fitted tidal amplitudes, not the instantaneous magnitudes of tidal oscillations. Therefore, our results can factually illustrate the variation of the tidal structure, which is due to the nonlinear processes.

\subsection{Model examination}

To examine our tidal models, we first calculated the linear propagation solution of the migrating semidiurnal tide by adopting the GSWM-00 results as initial tidal disturbances and employing the same background atmosphere, tidal forcing and dissipation schemes as those in the GSWM-00. As mentioned above, under completely identical conditions after dropping the time-dependant factor $e^{i n(\Omega t+\lambda)}$, our linear propagation solutions should be equal to the GSWM-00 results, namely our linear model should retain the initial tidal amplitudes and phases unchanged.

The migrating semidiurnal tide dominates over the migrating diurnal tide at latitudes from $\sim 50^{\circ} \mathrm{N} / \mathrm{S}$ to $\sim 70^{\circ} \mathrm{N} / \mathrm{S}$ above $90 \mathrm{~km}$ in the MLT region. The GSWM-00 predicts that the migrating semidiurnal tide is hardly hemispherically symmetric, except for March, and displays remarkable monthly variation: it maximizes during March and minimizes during June. For the entire year, the zonal- and meridional-wind amplitudes maximize at $45-60^{\circ} \mathrm{N} / \mathrm{S}$, but the exact latidude-altitude locations and maximum amplitudes exhibit a strong month-to-month variation. Although 


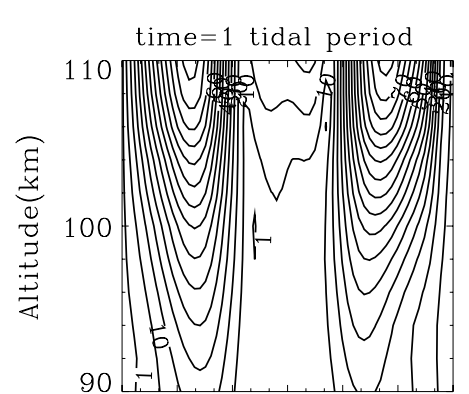

$90 \quad 6030 \quad 0 \quad-30-60-90$

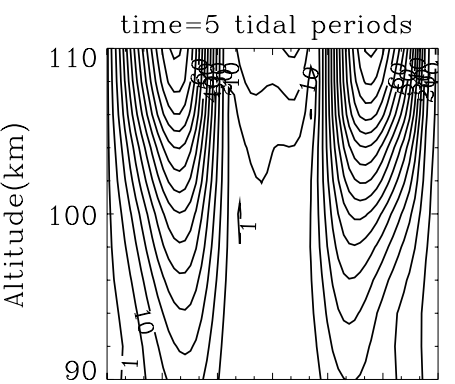

$90 \quad 60 \quad 30 \quad 0 \quad-30-60-90$ Latitude(Degree)

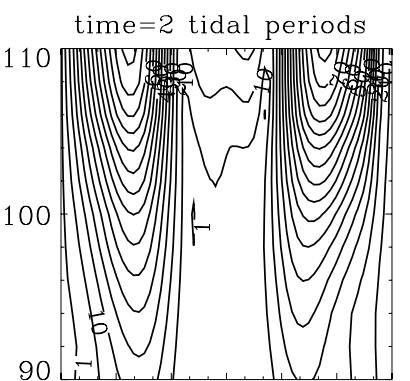

$90 \quad 6030 \quad 0 \quad-30-60-90$

time $=6$ tidal periods

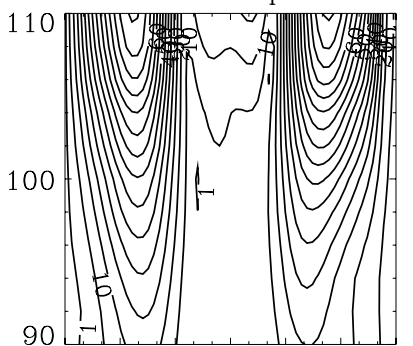

$90 \quad 60 \quad 30 \quad 0 \quad-30-60-90$

Latitude(Degree)

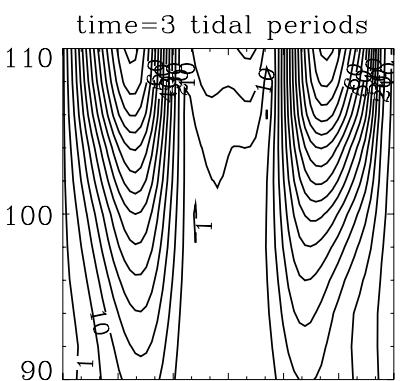

$90 \quad 60 \quad 30 \quad 0 \quad-30-60-90$

time $=7$ tidal periods

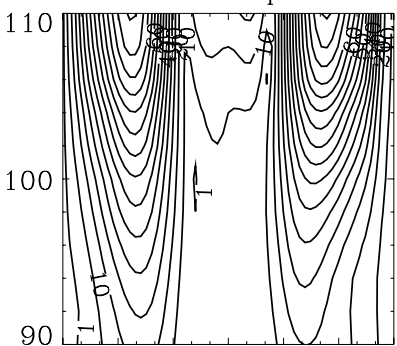

$90 \quad 60 \quad 30 \quad 0 \quad-30-60-90$

Latitude(Degree)

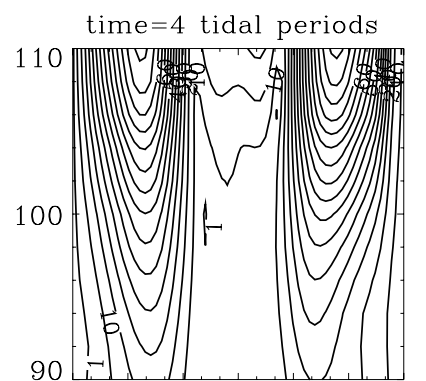

$90 \quad 60 \quad 30 \quad 0 \quad-30-60-90$

time $=8$ tidal periods

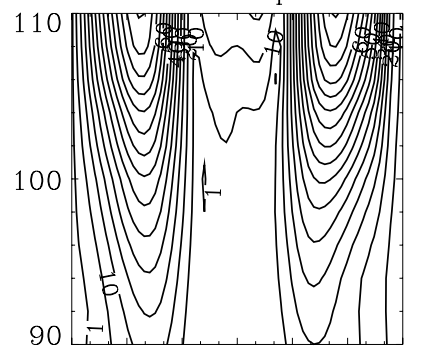

$90 \quad 60 \quad 30 \quad 0 \quad-30-60-90$ Latitude(Degree)

Fig. 1. Temporal evolution of the zonal-wind amplitudes within 8 tidal periods for March deduced from the linear propagation solution of the migrating semidiurnal tide starting from the GSWM-00 tidal oscillations. The minimum values of the contours are $1 \mathrm{~ms}^{-1}$, and the intervals of the contours are $5 \mathrm{~ms}^{-1}$ when the amplitudes are greater than $5 \mathrm{~m} / \mathrm{s}$.

we have carried out monthly linear simulations, for reasons of space, only the result for March is presented here. In March, the zonal-wind component of the migrating semidiurnal tide predicted by GSWM-00 is almost hemispherically symmetric and has two large-amplitude regions centered at $54^{\circ} \mathrm{N} / \mathrm{S}$. Figure 1 is the time evolution of the zonal-wind amplitudes within 8 tidal periods (4 days for the semidiurnal tide) conducted from our linear model. It shows that the amplitudes are in excellent agreement with those from the GSWM-00 at altitudes $0-110 \mathrm{~km}$ and are nearly constant with time. We numerically compared the amplitudes from these two linear models in detail. The comparisons indicate that they accord well with each other in most computational regions. Below $110 \mathrm{~km}$, the maximum difference is $1.1 \mathrm{~ms}^{-1}$ (vs. the maximum amplitude of $77.7 \mathrm{~ms}^{-1}$ ), confirming that our linear model (including algorithm and coding) is reliable. The same conclusion can be obtained from the linear simulations for the other 11 months.

Since we adopted the identical temporal integration and spatial difference methods in resolving the nonlinear Eqs. (1) and linear Eqs. (2), the differences between the results of our nonlinear model (i.e. the nonlinear propagation solutions) and the GSWM-00 (i.e. the linear steady-state solutions) actually reveal the impact of the nonlinear processes on the tidal structure. In this study, we focus on the amplitude structure on the basis of the monthly background atmosphere.
Moreover, it is well known that in a linear regime, the background atmosphere will remain unchanged. For observing the alteration of the background atmosphere, we fit our linear propagation solution according to Eq. (3) to obtain the time-dependent mean flow alteration (i.e. $\left.\boldsymbol{f}_{0}(\varphi, r, t)\right)$. Within 8 wave periods, the maximum alteration of background zonal wind is $1.03 \times 10^{-4} \mathrm{~ms}^{-1}$ (the figure not presented here), which reveals that there is indeed no evident mean-flow change in our linear propagation solutions and further verifies that our linear model is reliable.

\section{Nonlinear simulation results}

\subsection{Tidal amplitude structure variation}

Obviously the GSWM-00 linear tidal solutions satisfy our linear equations, namely Eqs. (2), but do not satisfy our nonlinear equations, namely Eqs. (1). Initialized by the GSWM00 results, our nonlinear propagation solutions of the migrating semidiurnal tide may deviate from the initial tidal oscillations since the nonlinear terms are switched on. We will compare the fitted tidal amplitudes from our nonlinear simulations with those from the GSWM-00. Their amplitude differences expressed by subtracting the GSWM-00 results from our nonlinear model results can represent the impact 
of nonlinear processes on the tidal amplitude and can be regarded as the nonlinearity-induced tidal variation.

Firstly, we present the time evolution of the tidal amplitude difference. It is well known that the migrating semidiurnal tide shows a remarkable month-to-month variation. Accordingly, we carried out monthly nonlinear simulations to study the monthly characteristics of the nonlinearity-induced tidal variation. However, for reasons of space and a clearer illustration, we only present the simulations for two representative months, i.e. March and June. The simulations for the other 10 months will be referred to, where necessary.

Below $90 \mathrm{~km}$, there is no appreciable tidal amplitude difference, which may be attributed to the small tidal amplitudes at that location. Therefore, in the following text, we only present the computational results in the height range of 90-110 km.

Figure 2 is the time evolution of the amplitude difference of the semidiurnal zonal-wind tide within 8 wave periods for March. It can be seen that the magnitudes of the amplitude differences become larger and larger with time at the beginning and the increase tendency is kept within the first 5 tidal periods. After 6 periods, they vary slightly. Detailed numerical analyses denote that their differences are less than $1.0 \mathrm{~ms}^{-1}$, indicating that the nonlinear model reaches a quasi-steady state. Furthermore, the nonlinear tidal amplitude within 8 wave periods evidently shows the uniform variation tendency: in the MLT region, the amplitudes are intensively strengthened in equatorial region and intensively weakened at middle and high latitudes centered at $54^{\circ} \mathrm{N} / \mathrm{S}$, the inertial latitudes of the semidiurnal zonal-wind tide.

Figure 3 is same as Fig. 2 but for June. It displays the similar evolution tendency. After 6 periods, their differences are less than $0.5 \mathrm{~ms}^{-1}$. The nonlinear tidal amplitudes within 8 wave periods also show the uniform variation tendency: in the MLT region, the amplitudes are slightly strengthened at latitudes from $12^{\circ} \mathrm{N}$ to $45^{\circ} \mathrm{S}$ and slightly weakened at other latitudes.

From the above results, we can conclude that the tidal amplitude variation arising from nonlinear processes has an evident period-to-period variation at the beginning, and its magnitudes show a notable increase with time. The variation tendency is kept until the model reaches a quasi-steady state, implying that this variation is irreversible. Its large magnitudes at the quasi-steady state reveal that the nonlinearinduced tidal variation is very significant and cannot be neglected. Considering that the nonlinear model is remaining at the quasi-steady state after 8 wave periods, hereinafter we only present the results after 8 wave periods to illustrate the tidal structure variation. The maxima (minima) of the variation magnitude in the zonal wind for March and June are, respectively, $15.8(-15.3) \mathrm{ms}^{-1}$ and $7.7(-5.3) \mathrm{ms}^{-1}$.

Some characteristics of tidal amplitude variation of the migrating semidiurnal tide can be found from our monthly simulations: significant magnitudes only appear above $100 \mathrm{~km}$, where the GSWM-00 predicts large tidal amplitudes; the magnitudes and latitudinal distributions for 12 months of the year are much different from each other; it can be described by the same annual cycle as the semidiurnal tidal amplitudes themselves. It is very clear from Figs. 2 and 3 that the zonalwind amplitude difference shows striking monthly features: it is very significant in March while rather weak in June, denoting that the significant variation often accompanies the large tidal amplitudes (implying strong nonlinear effect). In March, the tidal amplitude variation exhibits a hemispheric symmetry, which may be attributed to the hemispheric symmetry of the tidal zonal-wind amplitudes.

Figure 4 shows the tidal amplitude difference in temperature for March and June. Many features discussed above are also better seen in Fig. 4, such as height distributions and monthly variations. During March, the amplitude increases and decreases appear alternatively with latitudinal variation: three distinct amplitude-decreasing regions are centered, respectively, at $\sim 6^{\circ} \mathrm{S}$ and $\sim 45^{\circ} \mathrm{N} / \mathrm{S}$ and four distinct amplitude-increasing regions are centered, respectively, at $\sim 21^{\circ} \mathrm{N} / \mathrm{S}$ and $\sim 60^{\circ} \mathrm{N} / \mathrm{S}$. During June, the temperature amplitudes evidently decrease at $33^{\circ} \mathrm{N}$ and $108 \mathrm{~km}$. The maximum increase $(14.7 \mathrm{~K})$ and decrease $(-11.6 \mathrm{~K})$ in March is more pronounced than those $(3.0 \mathrm{~K}$ and $-5.3 \mathrm{~K})$ in June. Figures 2, 3 and 4 indicate that nonlinear processes can intensively impact the tidal structures and lead to notable structure variation of the migrating semidiurnal tide in the MLT region above $100 \mathrm{~km}$, especially in the month with a strong semidiurnal tide.

Moreover, we expand the semidiurnal temperature for March for the GSWM-00 result and the nonlinear fitted result at the quasi-steady state based on the normalized semidiurnal migrating Hough Functions. We find that above $100 \mathrm{~km}$, the coefficient of $(2,12)$ Hough mode for the nonlinear result is evidently larger than that for the GSWM-00 result, which implies that the nonlinear interactions can enhance the highorder symmetric Hough modes in the tidal solution at altitudes above $100 \mathrm{~km}$.

\subsection{Background alterations}

In this section we are interested in presenting the background alterations due to the nonlinear propagation of the migrating semidiurnal tide. Similarly to the previous subsection, our illustration concentrates on the zonal-wind and temperature components. It is well known that the nonlinear tide-mean flow interaction can induce alterations in the dynamical and thermal structures of the background atmosphere, which obviously cannot be revealed by any linear model, such as the GSWM-00. Our nonlinear model allows us to explore quantitatively the nonlinear interactions on the monthly climatology of the background atmosphere. By fitting our nonlinear propagation solution according to Eq. (3), we can obtain the time-dependent mean flow. After subtracting the prescribed mean flow, we can obtain the mean flow alteration. The presented background alterations are also seen in the results 

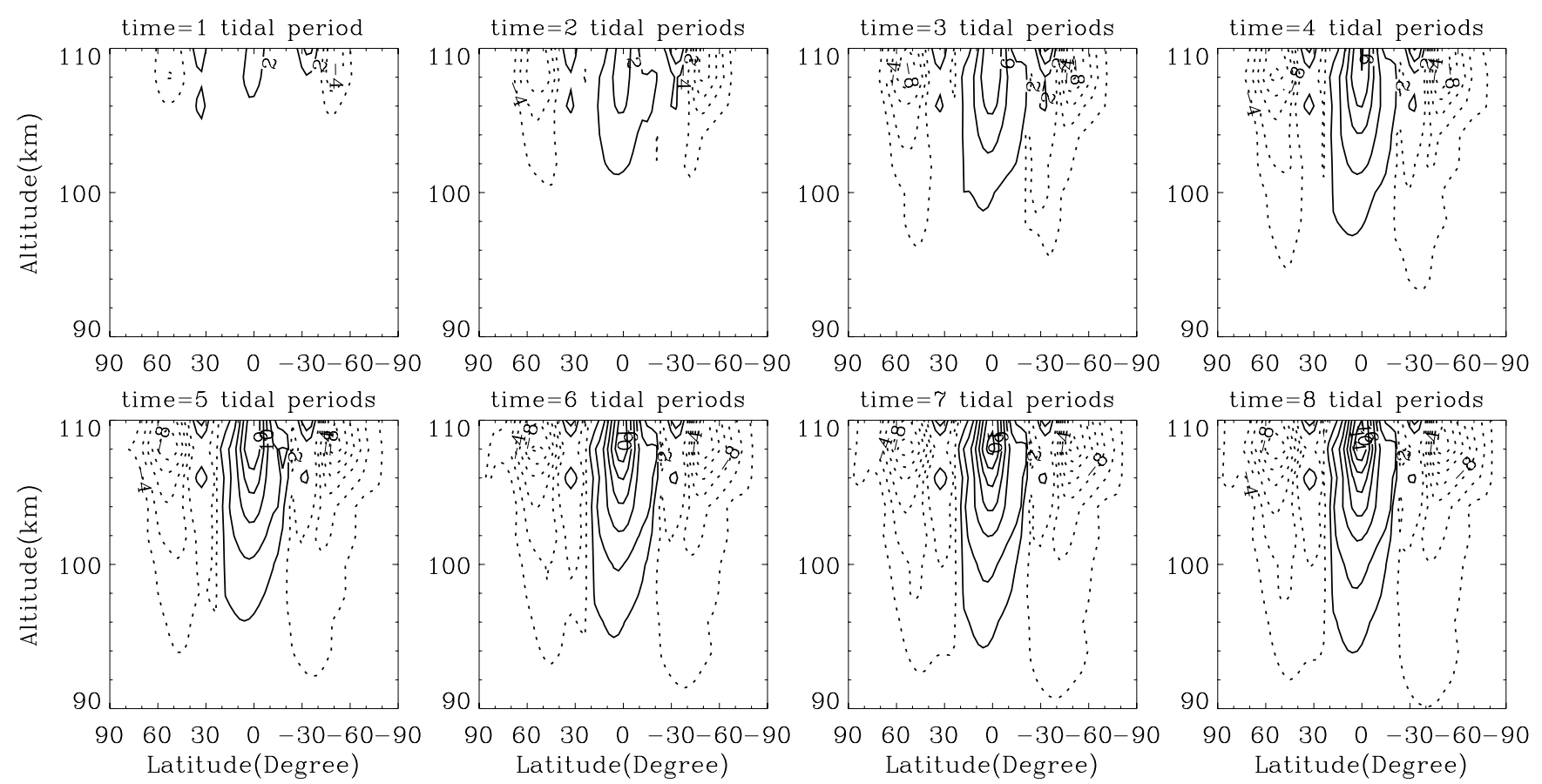

Fig. 2. Temporal evolution of the zonal-wind amplitude difference (specified by subtracting the GSWM-00 results from the nonlinear model results) within 8 tidal periods for March deduced from the nonlinear propagation solution of the migrating semidiurnal tide starting from the GSWM-00 tidal oscillations. The intervals of the contours are $2 \mathrm{~ms}^{-1}$. The solid and dotted curves denote the positive and negative values, respectively.

after 8 tidal periods. As noted in Sect. 2.5, when tides propagate in a linear regime, there is no appreciable background alteration. Therefore, the background alterations emerging in a nonlinear regime should be attributed to the tide-mean flow interaction. Figures 5 and 6 are the alterations of the background zonal wind and temperature, respectively. Some characteristics presented in Figs. 2, 3 and 4 can also been observed in Figs. 5 and 6, such as large magnitudes above $100 \mathrm{~km}$, monthly variation and hemispherical symmetry for March while hemispherical asymmetry for June. It can be seen from Fig. 5 that in March, the background zonal winds evidently change at middle and high latitudes. They are decelerated in middle latitudes centered $\sim 39^{\circ} \mathrm{N} / \mathrm{S}$ while accelerated at high latitudes greater than $\sim 60^{\circ} \mathrm{N} / \mathrm{S}$, and the deceleration effects are more pronounced. In June, large alterations occur at middle latitudes in the Southern Hemisphere. The maximum decrease in March is $-21.4 \mathrm{~ms}^{-1}$ while that in June is $-9.8 \mathrm{~ms}^{-1}$.

The common feature of the background temperature alterations during March and June is that the warming-up and cooling-down regions appear alternatively with latitude. In March, three distinct warming-up regions are centered, respectively, at $\sim 0^{\circ}$ and $\sim 30^{\circ} \mathrm{N} / \mathrm{S}$ and four distinct cooling-down regions are centered, respectively, at $\sim 15^{\circ} \mathrm{N} / \mathrm{S}$ and $\sim 51^{\circ} \mathrm{N} / \mathrm{S}$. During June, the background atmosphere is warmed up around $\sim 25^{\circ} \mathrm{N} / \mathrm{S}$, and cooled down around $\sim 43^{\circ} \mathrm{N} / \mathrm{S}$. The maximum increase $(57.9 \mathrm{~K})$ and decrease $(-52.9 \mathrm{~K})$ in March are with rather large magnitudes, which are more pronounced than those $(15.2 \mathrm{~K}$ and $-16.3 \mathrm{~K})$ in June.

Figures 5 and 6 demonstrate that the nonlinear propagation of the migrating semidiurnal tide can intensively affect the transient dynamical and thermal structures of the background atmosphere in the MLT region.

\section{Numerical convergence}

In this section we give the linear and nonlinear model results for March, starting from zero tidal oscillations, to help assess the numerical convergence of our tidal models, to further verify that the above presented results are reliable. Figure 7 is the linear tidal evolution in the zonal wind within 10 tidal periods. From this figure we note that tidal amplitudes gradually approach the GSWM-00 values. Detailed data analyses on the simulations of every tidal period yield that the amplitudes increase rapidly and exceed the GSWM-00 values in most regions within 1 period, then oscillate around them, and finally approach them. After 8 periods, the absolute differences between our linear results and the GSWM-00 values in the zonal-wind tidal component are less than $2.5 \mathrm{~ms}^{-1}$. So, we can conclude that our linear model starting from zero 

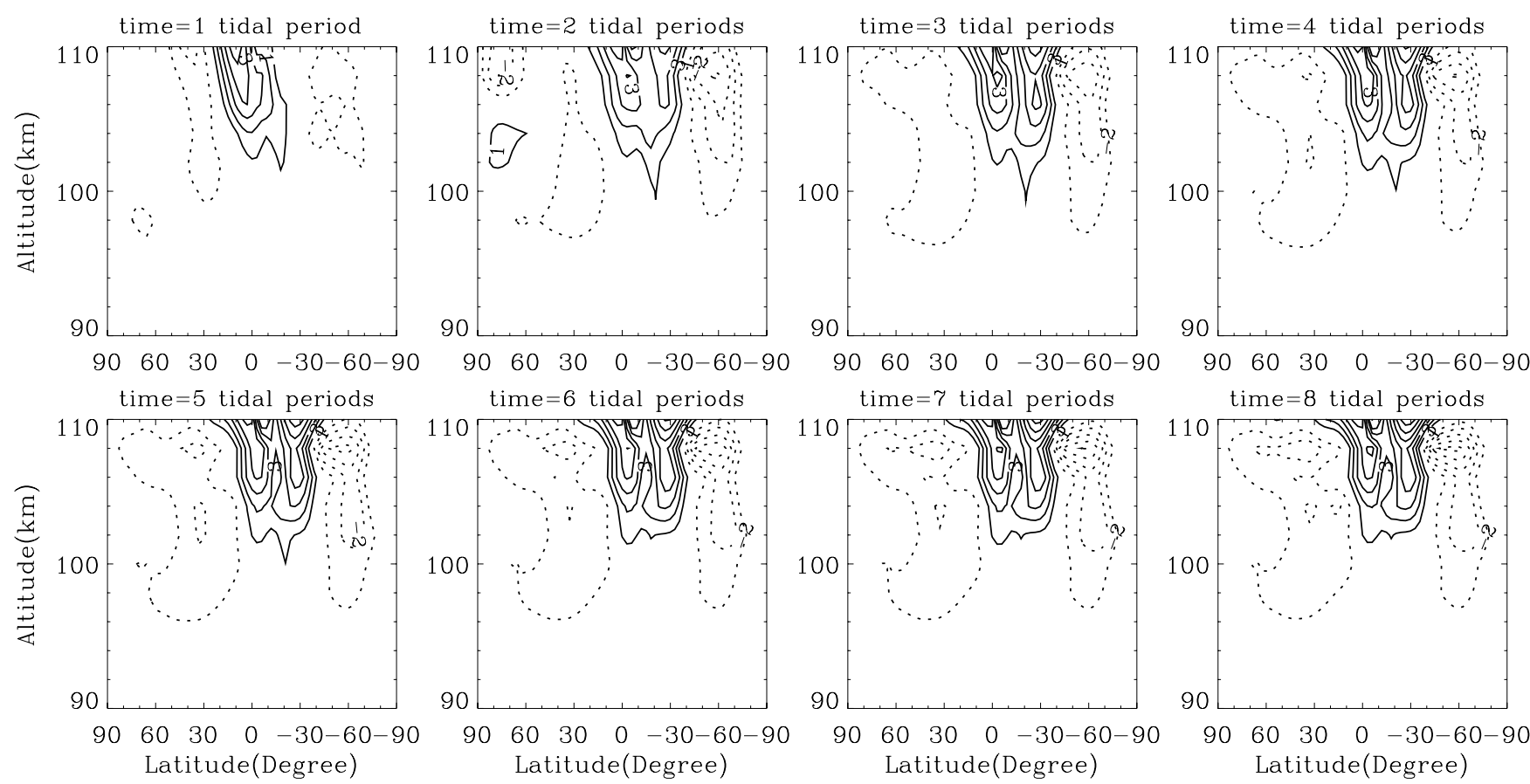

Fig. 3. Same as Fig. 2 but for June. The intervals of the contours are $1 \mathrm{~ms}^{-1}$. The solid and dotted curves denote the positive and negative values, respectively.
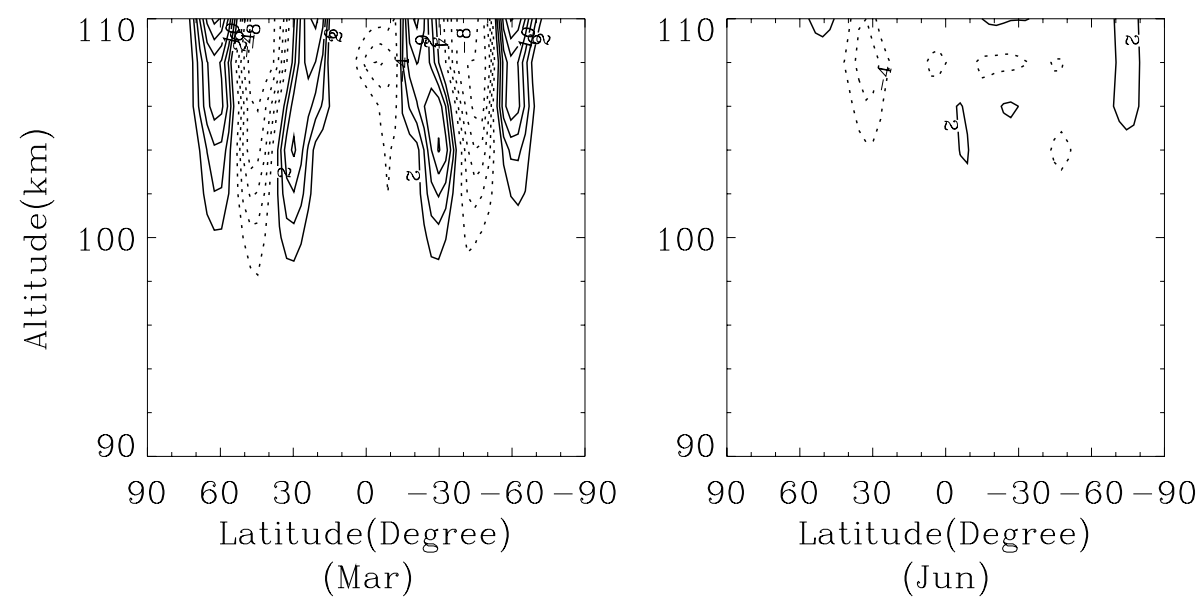

Fig. 4. Temperature amplitude differences after 8 tidal periods for March (left) and June (right) deduced from the nonlinear propagation solutions of the migrating semidiurnal tide starting from GSWM-00 tidal oscillations. The intervals of the contours are $2 \mathrm{~K}$. The solid and dotted curves denote the positive and negative values, respectively.

tidal oscillations can reach the GSWM-00 results after 8 periods of integration, manifesting the numerical convergence and reliability of our linear model. Figure 8 is the time evolution of the tidal amplitude difference in the zonal wind within 10 tidal periods. It can be observed that even if starting from zero tidal oscillations, the nonlinear model can also gradually reach a quasi-steady state. Detailed quantitative analyses indicate that after 8 periods, the variation magnitudes of tidal amplitudes are less than $3.0 \mathrm{~ms}^{-1}$. Comparing the results after 8 periods, starting from GSWM-00 tidal oscillations and zero tidal oscillations, we find that their absolute differences are less than $3.0 \mathrm{~ms}^{-1}$. So, it validates the numerical convergence of our nonlinear model. 

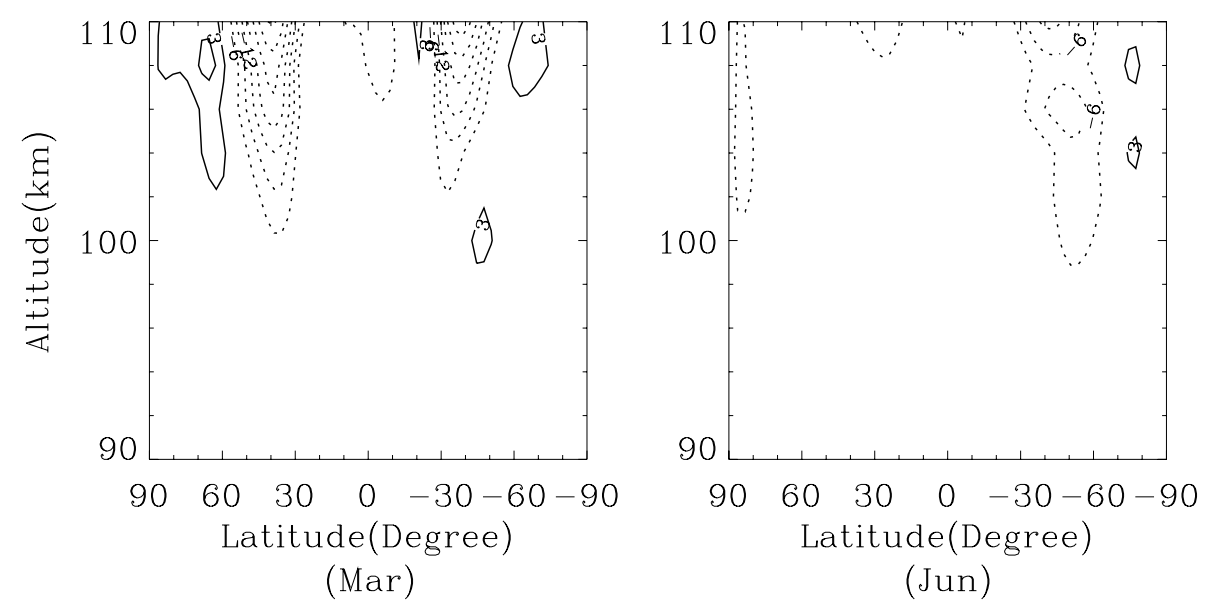

Fig. 5. Background zonal-wind alterations after 8 tidal periods for March (left) and June (right) deduced from the nonlinear propagation solutions of the migrating semidiurnal tide starting from the GSWM-00 tidal oscillations. The intervals of the contours are $3 \mathrm{~ms}{ }^{-1}$. The solid and dotted curves denote the positive and negative values, respectively.
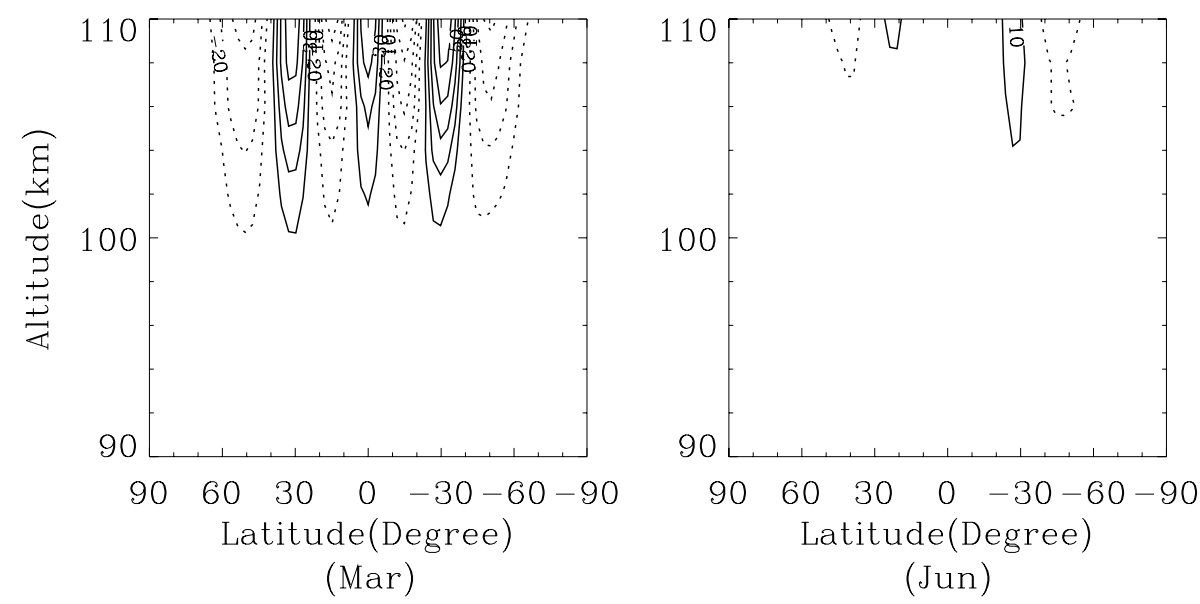

Fig. 6. Same as Fig. 5 but for background temperature alterations for March (left) and June (right). The intervals of the contours are $10 \mathrm{~K}$. The solid and dotted curves denote the positive and negative values, respectively.

\section{Discussions}

Our nonlinear simulations demonstrate well the pronounced and irreversible impact of nonlinear interactions on the semidiurnal tidal amplitude and mean flow. There are some issues which should be addressed here.

The first issue is that the numerical examination (presented in Sect. 2.5) and convergence check (presented in Sect. 4) have confirmed that our tidal models (mainly including algorithm and coding) are reliable and with a high degree of accuracy. For testing the accuracy of the integration algorithm adopted in our model, and more important, for verifying that the presented tidal amplitude difference represents the realistic effects of nonlinear dynamics rather than the numerical effects due to the specification of the upper boundary, we compare the linear model results within 8 wave periods with the GSWM-00 and find that they are in excellent agreement in most computational regions. Below $110 \mathrm{~km}$, the amplitude differences in the zonal wind for March are very small, with the maximum magnitude of $1.1 \mathrm{~ms}^{-1}$, which are at least one order smaller than the maximum magnitude of the tidal amplitude difference $\left(15.8 \mathrm{~ms}^{-1}\right)$, suggesting that the numerical effects of our linear model are negligible. Since completely identical spatial differential and temporal integration methods were adopted in our nonlinear model, the reliability of the linear model results can partly ensure that the numerical error of the nonlinear model results are restricted to within a very small range. Additionally, in order to manifest that the presented tidal difference is indeed due to nonlinearity rather than numerical adjustment of the initial wave disturbances, we provide the linear and nonlinear model results, starting from zero tidal oscillations. Detailed quantitative analyses 

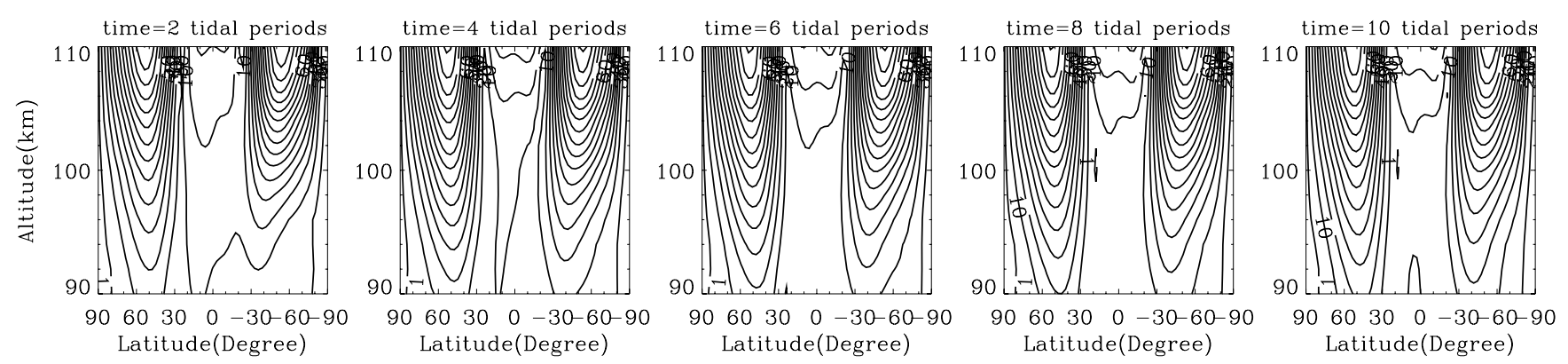

Fig. 7. Temporal evolution of the zonal-wind amplitudes within 10 tidal periods for March deduced from the linear propagation solution of the migrating semidiurnal tide starting from zero tidal oscillations. The minimum values of the contours are $1 \mathrm{~ms}^{-1}$, and the intervals of the contours are $5 \mathrm{~ms}^{-1}$ when the amplitudes are greater than $5 \mathrm{~m} / \mathrm{s}$.
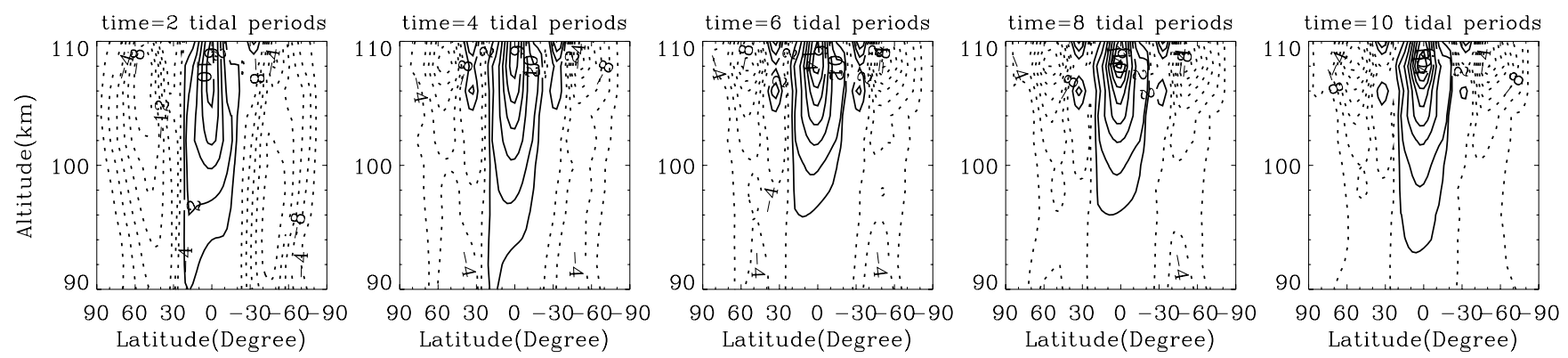

Fig. 8. Temporal evolution of the zonal-wind amplitude difference within 10 tidal periods for March deduced from the nonlinear propagation solution of the migrating semidiurnal tide starting from zero tidal oscillations. The intervals of the contours are $2 \mathrm{~ms}^{-1}$. The solid and dotted curves denote the positive and negative values, respectively.

denote that our models can eventually approach the identical state if a difference of $3.0 \mathrm{~ms}^{-1}$ in the zonal wind is allowed regardless whether one starts from the GSWM-00 tidal oscillations or from the zero tidal oscillations. Therefore, our nonlinear model results should be believable and the presented variations of the tidal amplitude and mean flow factually arise from the nonlinear interactions.

The second issue is that since the results presented in this paper are all the fitted tidal amplitudes, our results factually illustrate the variations of the wave structure rather than the periodic oscillations of the wave disturbances. Observing the evolution of the tidal amplitude variation, we can see that its magnitude exhibits an increase tendency within the first several periods, and finally reaches a quasi-steady state. Therefore, the nonlinear-induced tidal structure variation is believed to be irreversible. It should be noted that the GSWM-00 result is a linear steady solution under the specified thermotidal heating, dissipative terms and background atmosphere, while our nonlinear model result represents the quasi-steady solution when nonlinear interactions are taken into account under the same conditions.

As stated above, our simulation results reveal that the nonlinear interactions may lead to a pronounced structure variation of the migrating semidiurnal tide. Regarding the tidal amplitudes, our simulation results show some agree- ment with certain observations in some disagreement with the GSWM-00, suggesting that the nonlinear effect could be an important cause of the discrepancy between the observation and the GSWM-00. Palo et al. (1997) provided a comparison between the GSWM, UARS, and ground-based radar observations in January 1993, and found that there were a number of cases where their agreement was not particularly good between 95 and $105 \mathrm{~km}$. One such instance is for the meridional semidiurnal tide in the Northern Hemisphere, where the GSWM estimates may exceed observations by $50 \%$. Here, we presented the nonlinearity-induced amplitude difference of the meridional semidiurnal tide during January (left panel of Fig. 9). We can see that in most regions of the Northern Hemisphere, the variation is negative and very strong, which means that the meridional-wind amplitudes of the semidiurnal tide from our nonlinear model are smaller than the GSWM-00 and consistent with the observations. Wu et al. (2006) compared the TIDI observations with the GSWM-00 output for April between 85 and $110 \mathrm{~km}$, and found that the Southern Hemisphere amplitudes shown by the TIDI data are much weaker than those predicted by the GSWM-00. Here, for comparison, we presented the nonlinearity-induced amplitude difference of the meridional semidiurnal tide during April (right panel of Fig. 9). Evidently, in the Southern Hemisphere, there are large negative 

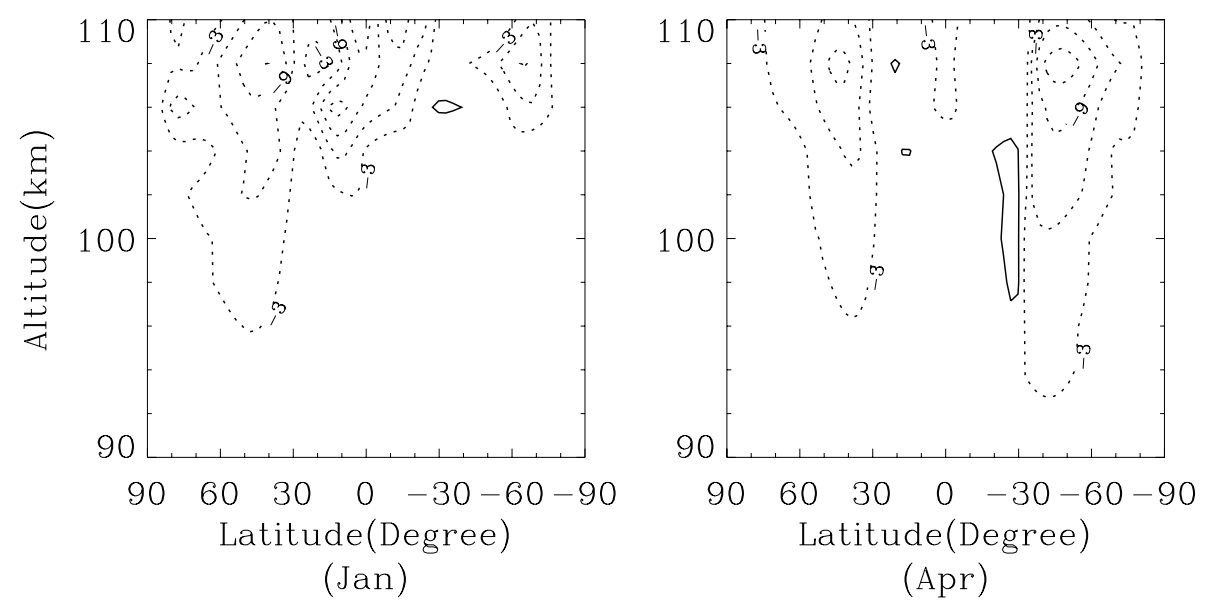

Fig. 9. Meridional-wind amplitude differences after 8 tidal periods for January (left) and April (right) deduced from the nonlinear propagation solutions of the migrating semidiurnal tide starting from the GSWM-00 tidal oscillations. The intervals of the contours are 3 ms ${ }^{-1}$. The solid and dotted curves denote the positive and negative values, respectively.

values, also indicating that the meridional-wind amplitudes of the semidiurnal tide from our nonlinear model are smaller than the GSWM-00 and in agreement with the observations. Therefore, to some extent, our nonlinear model results can be used to quantitatively elucidate some physical mechanisms accounting for the discrepancies between the GSWM-00 and global observations.

The third issue is that some potential dissipation mechanisms are not taken into consideration, both in our study and the GSWM-00, such as the nonlinear interactions among different atmospheric wave modes (tides, planetary waves and gravity waves). In fact, many theoretical and observational works have revealed that these interactions are ubiquitous in the real middle and upper atmosphere, e.g. the interactions between different tidal components presented by Teitelbaum et al. (1989), Smith (2000) and Zhang et al. (2004), tides and planetary waves by Hagan and Roble (2001) and Mayr et al. (2003) and tides and gravity waves by Miyahara and Forbes (1991) and Lu and Fritts (1993). These interactions may also lead to the disagreement of the observed tidal amplitudes with the GSWMs at altitudes above $90 \mathrm{~km}$ (Burrage et al., 1995; Palo et al., 1997; Bruinsma et al., 2002; Grieger et al., 2002; Pancheva et al., 2002; She et al., 2003; Batista et al., 2004; Zhang et al., 2004; Wu et al., 2006), in addition to the nonlinear interactions discussed in this paper. The very large alterations in the background temperature $(57.9 \mathrm{~K}$ and $-52.9 \mathrm{~K}$ ) deduced from our nonlinear model may be due to the absent of these dissipation mechanisms. Therefore, in a sequential work, we will focus on the nonlinear resonance interaction between the diurnal and semidiurnal tides.

The last issue is that in our tidal models, the prescribed mean flow is the same as that employed by the GSWM-00, which are monthly averaged values, implying that in each simulation case, the mean flow is assumed to be almost timeindependent except for the nonlinearity (tide-mean flow in- teraction) induced variation. Since the presented background variations are not beyond 10 wave periods ( 5 days for the model simulations starting from zero tidal oscillations), such an assumption is basically appropriate.

An essentially linear model, such as the GSWM-00, cannot present the background field alterations resulting from the tide-mean flow nonlinear interaction. Our nonlinear model can facilitate correlative studies and our simulation results have displayed such rather significant alterations (with maximum magnitudes of $21.3 \mathrm{~ms}^{-1}$ for zonal-wind field and $57.9 \mathrm{~K}$ for temperature field), suggesting that for a further understanding global dynamics of the MLT region, the influences of tide-mean flow interactions should be seriously studied.

Additionally, we would like to explore the physical cause for our nonlinear results. It is well known that some waves with periods other than $12 \mathrm{~h}$ would be generated when the semidiurnal tide is propagating in a nonlinear regime. For making clear which waves are excited, we recorded 24$\mathrm{h}$ time sequences of the zonal wind disturbances at three selected spatial nodes, which are, respectively, located at $\left(180^{\circ}, 45^{\circ} \mathrm{S}, 108 \mathrm{~km}\right),\left(180^{\circ}, 45^{\circ} \mathrm{N}, 108 \mathrm{~km}\right)$, and $\left(180^{\circ}, 0^{\circ}\right.$, $108 \mathrm{~km}$ ), where significant tidal differences occur (shown in Fig. 2). These time sequences are recorded from $72 \mathrm{~h}$ (when the model is at the quasi-steady state) to $96 \mathrm{~h}$ at a $30-\mathrm{min}$ interval. We carried out discrete-time Fourier transforms on these time sequences and Fig. 10 is the spectral result. It is very clear from this figure that besides the prominent peaks at $n=2$ (12-h period), evident 6-h $(n=4)$ and 4-h $(n=6)$ tidal components also appear in our nonlinear simulation, and no significant diurnal and terdiurnal tidal components are observed. Such a result indicates that some new tidal components can be excited by nonlinearity and it cannot be revealed by any linear model. 


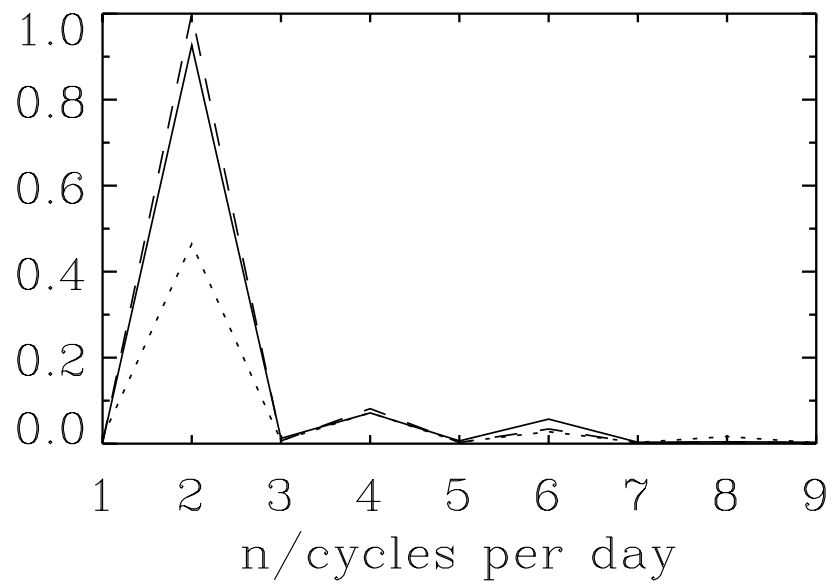

Fig. 10. Normalized frequency spectra of zonal wind disturbances at three selected points, which are respectively located at $\left(180^{\circ}, 45^{\circ} \mathrm{S}\right.$, $108 \mathrm{~km}$ ) (solid line), $\left(180^{\circ}, 45^{\circ} \mathrm{N}, 108 \mathrm{~km}\right)$ (dashed line) and $\left(180^{\circ}, 0^{\circ}, 108 \mathrm{~km}\right)$ (dotted line).
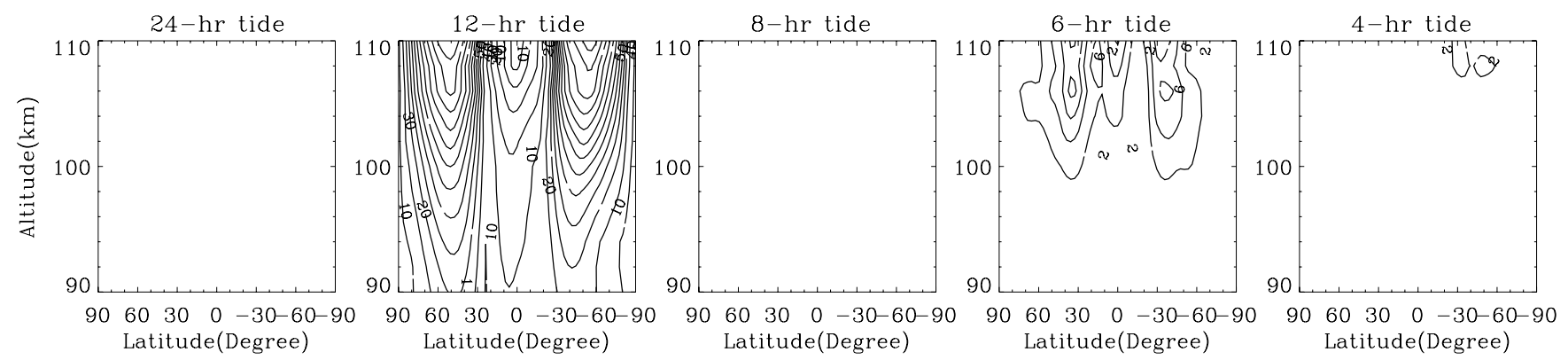

Fig. 11. Five tidal component amplitudes in the zonal wind for March. For the 12 -h tide the minimum value of the contour is $1 \mathrm{~ms}{ }^{-1}$, and the intervals of the contours are $5 \mathrm{~ms}^{-1}$ when the amplitudes are greater than $5 \mathrm{~ms}^{-1}$. For the other components, the minimum values and intervals of the contours are $2 \mathrm{~ms}^{-1}$.

Then, we would like to provide some physical insight as to why the 6-h and 4-h tides could be generated. We know that in a nonlinear regime, a quadratic harmonic will be generated by nonlinearity (Zhang and Yi, 2004). Considering that the migrating semidiurnal tide is with a frequency in cycles per day, $\mathrm{n}_{1}=2$, and a wave number, $\mathrm{s}_{1}=2$, the nonlinearity excited quadratic harmonic should have a frequencywave number pair $\left(n_{2}, s_{2}\right)=\left(2 n_{1}, 2 s_{1}\right)=(4,4)$, i.e. the migrating 6-hr tide. Subsequently, the excited 6-h wave may resonantly interact with the original 12 -h wave to create the other two waves with frequency-wave number pairs: $\left(\mathrm{n}_{2}+\mathrm{n}_{1}\right.$, $\left.\mathrm{s}_{2}+\mathrm{s}_{1}\right)=(6,6)$ and $\left(\mathrm{n}_{2}-\mathrm{n}_{1}, \mathrm{~s}_{2}-\mathrm{s}_{1}\right)=(2,2)$. They are, respectively, migrating 4-h and 12-h tides. The above nonlinear interaction mechanism has been clearly elucidated by Angelats i Coll and Forbes (2002). These nonlinear processes explain why we can observe 6-h and 4-h rather than 24-h and 8-h tidal components in Fig. 10. More important is that the resonant interaction between the initially given semidiurnal tide and the nonlinearity excited 6-h tide can generate a new migrating semidiurnal tide, which will further alter the initial semidiurnal tidal structure. Our speculation implies that the variation in the semidiurnal tidal structure exhibited in our nonlinear simulation may be the result from the above nonlinear processes. For confirming our speculation, we want to compare the amplitudes of the different tidal components in our nonlinear solution. Since the generated tides are all migrating components, we can analyze the tide components in a spatial domain instead of in a temporal domain. In order to extract the tidal components (the first, second, third, fourth, and sixth harmonics) from our nonlinear simulation results, a cosine function is used to fit the computational results $\left(f_{c}(\lambda, \varphi, r, t)\right)$ based on the variable $\lambda$, that is:

$$
\begin{aligned}
\boldsymbol{f}_{c}(\lambda, \varphi, r, t)= & \boldsymbol{f}_{0}(\varphi, r, t)+\sum_{n=1,2,3,4,6} \\
& \boldsymbol{f}_{a n}(\varphi, r, t) \cos \left[n(\Omega t+\lambda)+\boldsymbol{f}_{p n}(\varphi, r, t)\right],(4)
\end{aligned}
$$

where $n=1(2,3,4,6)$ for the diurnal (semidiurnal, terdiurnal, 6-h, 4-h) component; $f_{0}(\varphi, r, t)$ is the mean flow; $\boldsymbol{f}_{a n}(\varphi, r, t)$ and $\boldsymbol{f}_{p n}(\varphi, r, t)$ are tidal amplitude and phase, respectively. Figure 11 presents the zonal-wind amplitude structures for the above five tidal components, deduced from the nonlinear, quasi-steady tidal solution for March. It can be clearly seen that the apparent 6-h and 4-h tides are excited by 
nonlinear interactions and the 6-h component is more significant than the 4-h component. At the quasi-steady state, the maximum amplitude of the generated 6 -h tide is $8.6 \mathrm{~ms}^{-1}$, appearing at $36^{\circ} \mathrm{N}$ and $106 \mathrm{~km}$, while the maximum amplitude of the generated 4-h tide is $2.8 \mathrm{~ms}^{-1}$, appearing at $33^{\circ} \mathrm{S}$ and $108 \mathrm{~km}$. Moreover, the amplitudes for the diurnal and terdiurnal tidal components are too weak to be observed.

Based on the above results, we can conclude that the main cause for the differences between the linear and our nonlinear results at the quasi-steady state of the semidiurnal tide is that the initial migrating 12-h tide will interact with the mean flow, as well as the nonlinearity excited 6-h tide, and subsequently yield a new 12 -h tidal part. In fact, the final migrating 12-h tide at the quasi-steady state is the result of the combination of the effects of these nonlinear processes.

\section{Conclusions}

In this paper, we developed a numerical tidal model based on the nonlinear Navier Stokes equations in spherical coordinates, to study the impact of nonlinear interactions on the amplitude structure of the migrating semidiurnal tide and the mean flow. Its numerical reliability and convergence are respectively checked by the numerical experiments by switching off the nonlinear terms and starting from zero tidal oscillations.

Initialized by the GSWM-00 tidal oscillations, our nonlinear tidal solution deviates from the GSWM-00 result gradually. This difference can be attributed to wave-mean flow and wave-wave nonlinear interactions. Observing the temporal evolution of the tidal amplitude difference, it can be concluded that its magnitude becomes larger and larger within the first several tidal periods and eventually reaches a quasisteady state. The pronounced difference at the quasi-steady state suggests that the nonlinear interactions can evidently influence the tidal structures in the MLT region, especially above $100 \mathrm{~km}$, and cannot be neglected in the study of tidal phenomena in this region. Moreover, the difference exhibits an obvious monthly behavior, i.e. very significant in March and very slight in June. The difference in March is almost hemispherically symmetric while that in June is hardly hemispherically symmetric. A quantitative analysis suggests that the main cause for the differences between the linear and our nonlinear results at the quasi-steady state of the semidiurnal tide is that the initial migrating $12-\mathrm{h}$ tide will interact with the mean flow, as well as the nonlinearity-excited 6-h tide, and subsequently yield a new 12-h tidal part. In fact, the final migrating $12-\mathrm{h}$ tide at the quasi-steady state is the result of these nonlinear processes.

Additionally, the simulation results also show that the tidemean flow nonlinear interaction will evidently alter the background wind and temperature fields, suggesting that the nonlinearity can impact intensively the global transient dynamical and thermal structures in the MLT region. Similar to the tidal amplitude variations, the nonlinear-induced alterations of the background fields vary greatly with the month, and the alteration magnitudes depend closely on the tidal amplitudes. The alterations in March are much more significant than those in June.

Although not all disagreements of the various models with observations can be explained by the nonlinear interactions, our simulations quantitatively exhibit the significant impact of nonlinear interactions on the global structures of the semidiurnal tide and background atmosphere. Therefore, in the study of atmospheric tides and global atmospheric dynamics in the MLT region, the nonlinear processes involved in the propagations of tides should be comprehensively considered, which can be revealed only by a nonlinear numerical model, as presented in this paper.

\section{Appendix A}

\section{Numerical implementation}

A1 Spatial difference equations and computational methods

The spectral method, wherein model scalar variables are naturally represented in terms of a truncated series in spherical harmonics, appears to be more appropriate for the study of global-scale wave phenomena. Therefore, computationally efficient models based on the spectral platform gain much popularity in the atmospheric research. While solving Eqs. (1) and (2), we apply spectral formulations in the zonal and meridional directions, and the finite differential method in the vertical direction. Since the solutions are periodic in the zonal direction, the Fourier collocation method (Canuto et al., 1988) is applied to obtain the spatial differentiation in this direction. Regarding the variable $\varphi$, a transformation as below is introduced: $x=\cos \left(\frac{\pi}{2}-\varphi\right)$. Then the Legendre spectral method is used regarding the variable $x$ and the Legendre-Gauss-Lobatto points is applied (Canuto et al., 1988). The nodes used can be expressed as:

$$
\left\{\begin{array}{l}
\lambda_{i}=\frac{2 \pi i}{N_{\lambda}}, i=0, \ldots, N_{\lambda}-1, \\
x_{0}=-1, x_{N_{\varphi}}=1, x_{j}\left(j=1, \ldots, N_{\varphi}-1\right) \text { zeroes of } L_{N_{\varphi}}^{\prime}(x), \\
r_{k}=r_{0}+k \cdot \Delta r, k=0, \ldots, N_{r} .
\end{array}\right.
$$

where, $N_{\lambda}, N_{\varphi}+1, N_{r}+1$, respectively, denote the node number in three spatial directions; $L_{N_{\varphi}}^{\prime}(x)$ is the derivative of Legendre polynomials $L_{N_{\varphi}}(x)$. Considering the spatial scales of the migrating semidiurnal tide, the zonal and vertical space step lengths, i.e. $\Delta \lambda$ and $\Delta r$ are, respectively, set to be $5^{\circ}$ and $2 \mathrm{~km}$. In the meridional direction, $N_{\varphi}$ is set to be 60 , and the corresponding meridional space step at $\Delta \varphi \approx 3^{\circ}$. The resolution of our simulations approximates that of the GSWMs.

According to the Fourier and Legendre spectral collocation methods described by Canuto et al. (1988), the spatial derivatives in the horizontal directions can be written as: 


$$
\begin{aligned}
& \left\{\begin{array}{c}
\left.\frac{\partial f_{S}(\lambda, \varphi, r, t)}{\partial \lambda}\right|_{\lambda=\lambda_{l}}=f_{\lambda}\left(\lambda_{l}, \varphi_{m}, r_{n}, t_{k}\right)=\sum_{j=0}^{N_{\lambda}-1}\left(D_{\lambda}\right)_{l j} f\left(\lambda_{j}, \varphi_{m}, r_{n}, t_{k}\right), \\
\varphi=\varphi_{m} \\
r=r_{n} \\
t=t_{k} \\
\left(D_{\lambda}\right)_{l j}=\left\{\begin{array}{l}
\frac{1}{2}(-1)^{l+j} \cot \left[\frac{(l-j) \pi}{N_{\lambda}}\right], l \neq j . \\
0, l=j
\end{array}\right.
\end{array}\right. \\
& \left\{\begin{aligned}
&\left.\frac{\partial f_{S}(\lambda, \varphi, r, t)}{\partial \varphi}\right|_{\lambda}=\lambda_{l}=f_{\varphi}\left(\lambda_{l}, \varphi_{m}, r_{n}, t_{k}\right)=\frac{\partial x}{\partial \varphi} f_{x}\left(\lambda_{l}, \varphi_{m}, r_{n}, t_{k}\right)=\sin \left(\frac{\pi}{2}-\varphi\right) \cdot \sum_{j=0}^{N_{\varphi}}\left(D_{\varphi}\right)_{m j} f\left(\lambda_{l}, \varphi_{j}, r_{n}, t_{k}\right), \begin{array}{rl}
\varphi=\varphi_{m} \\
r & =r_{n}
\end{array} \\
&\left(D_{\varphi}\right)_{m j}=\left\{\begin{array}{l}
\frac{L_{N}\left(x_{m}\right)}{L_{N}\left(x_{j}\right)} \frac{1}{x_{m}-x_{j}}, m \neq j \\
\frac{\left(N_{\varphi}+1\right) N_{\varphi}}{4}, m=j=0 \\
-\frac{\left(N_{\varphi}+1\right) N_{\varphi}}{4}, m=j=N_{\varphi} \\
0, o \text { therwise }
\end{array} .\right.
\end{aligned}\right.
\end{aligned}
$$

A finite-difference method is adopted to calculate the spatial derivative in the vertical direction

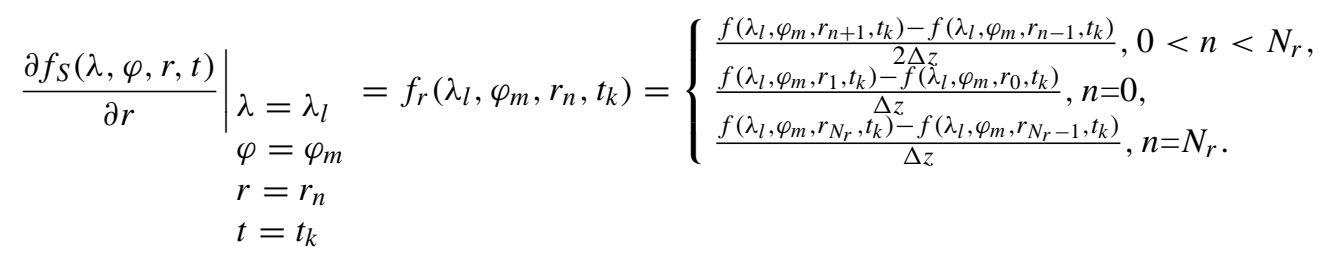

\section{A2 Temporal integration method}

An Eulerian implicit scheme is applied to guarantee the longterm stability. The dependent variables at the old (or given) time step are indicated by a superscript $n$, at the new time step (i.e. $(n+1)$ th time step) the $k$-th iterations are indicated by the superscript $k$. Then the resultant finite difference equations can be written as:

$\frac{\partial U}{\partial t}=G(U, t), \quad U^{k+1}=U^{n}+\Delta t G\left(U^{k+1}, t^{n+1}\right)$,

$k=1,2 \ldots$.

where $U=\left[u^{\prime} v^{\prime} w^{\prime} \rho^{\prime} T^{\prime}\right]$. Setting a tolerance error $\varepsilon$ to be $10^{-4}$, we repeat the iteration until the condition:

$\left|\frac{U^{k+1}-U^{k}}{U^{k}}\right|<\varepsilon$,

is satisfied and then set the iteration result to be $U^{n+1}$.

\section{Appendix B}

\section{Time step length}

For the explicit scheme applied in the specification of bottom and top boundary conditions, the time step-length should sat- isfy the stability condition:

$$
\Delta t<\Delta t_{c}=\frac{1}{\left(\mathrm{v}_{a}+v_{T}\right)\left[\frac{1}{\Delta r^{2}}+\frac{1}{(r \cos \varphi \Delta \lambda)^{2}}+\frac{1}{(r \Delta \varphi)^{2}}\right]^{\frac{1}{2}}},
$$

where, $v_{a}$ is the acoustic velocity, $v_{T}=\sqrt{\left(u_{0}+u^{\prime}\right)^{2}+\left(v^{\prime}\right)^{2}+\left(w^{\prime}\right)^{2}}$. In a practical calculation, for more accurate results with less iteration required for convergence under the same tolerance error, we choose $\Delta t=0.25 \Delta t_{c}$.

Acknowledgements. We would like to thank the editor and anonymous reviewers of this paper for their valuable suggestions. This work was jointly supported by the National Natural Science Foundation of China (through grant 40504018, 40336054 and 40575020), the Program for New Century Excellent Talents in University of China, the Cultivation Fund of the Key Scientific and Technical Innovation Project, Ministry of Education of China (No: 2004-295) and the Opening Foundation of SOA Key Laboratory for Polar Science (KP2005010).

Topical Editor U.-P. Hoppe thanks two referees for their help in evaluating this paper. 


\section{References}

Angelats i Coll, M. and Forbes, J. M.: Nonlinear interactions in the upper atmosphere: the $s=1$ and $s=3$ nonmigrating semidiurnal tides, J. Geophys. Res., 107(A8), 1157, doi:10.1029/2001JA900179, 2002.

Batista, P. P., Clemesha, B. R., Tokumoto, A. S., and Lima, L. M.: Structure of the mean winds and tides in the meteor region over Cachoeira Paulista, Brazil $\left(22.7^{\circ} \mathrm{S}, 45^{\circ} \mathrm{W}\right)$ and its comparison with models, J. Atmos. Sol-Terr. Phys., 66, 623-636, 2004.

Bruinsma, S., Vial, F., and Thuillier, G.: Relative density variations at $120 \mathrm{~km}$ derived from tidal wind observations made by the UARS/WINDII instrument, J. Atmos. Sol-Terr. Phys., 64, 13-20, 2002.

Burrage, M. D., Hagan, M. E., Skinner, W. R., Wu, D. L., and Hays, P. B.: Long-term variability in the solar diurnal tide observed by HRDI and simulated by the GSWM, Geophys. Res. Lett., 22, 2641-2644, 1995.

Canuto, C., Hussaini, M. Y., Quarteroni, A., and Zang, T. A.: Spectral methods in fluid dynamics, Springer-Verlag, New York, London, 1988.

Chapman S. and Lindzen, R. S.: Atmospheric Tides, 201 pp., D. Reidel, Norwell, Mass, 1970.

Fesen, C. G., Roble, R. G., and Ridley, E. C.: Thermospheric tides simulated by the National Center for Atmospheric Research Thermosphere-ionosphere General Circulation Model at equinox, J. Geophys. Res., 98, 7805-7821, 1993.

Forbes, J. M.: Atmospheric tides, 1. Model description and results for the solar diurnal component, J. Geophys. Res., 87, 52225240, 1982.

Forbes, J. M., Roble, R. G., and Fesen, C. G.: Acceleration, heating and compositional mixing of the thermosphere due to upwardpropagating tides, J. Geophys. Res., 98, 311-321, 1993.

Grieger, N., Volodin, E. M., Schmitz, G., Hoffmann, P., Manson, A. H., Fritts, D. C., Igarashi, K., and Singer, W.: General circulation model results on migrating and nonmigrating tides in the mesosphere and lower thermosphere, Part I: comparison with observations, J. Atmos. Sol-Terr. Phys., 64, 897-911, 2002.

Hagan, M. E., Forbes, J. M., and Vial, F.: On modeling migrating solar tides, Geophys. Res. Lett., 22, 893-896, 1995.

Hagan, M. E., Burrage, M. D., Forbes, J. M., Hackney, J., Randel, W. J., and Zhang, X.: GSWM-98: results for migrating solar tides, J. Geophys. Res., 104, 6813-6827, 1999.

Hagan, M. E., Roble, R. G., and Hackney, J.: Migrating thermospheric tides, J. Geophys. Res., 106, 12 739-12 752, 2001.

Hagan, M. E. and Roble, R. G.: Modeling diurnal tidal variability with the National Center for Atmospheric Research thermosphere-ionosphere-mesosphere-electrodynamics general circulation model, J. Geophys. Res., 106, 24 869-24 882, 2001.

Hagan, M. E. and Forbes, J. M.: Migrating and nonmigrating diurnal tides in the middle and upper atmosphere excited by tropospheric latent heat release, J. Geophys. Res., 107(D24), 4754, doi:10.1029/2001JD001236, 2002.

Hagan, M. E. and Forbes, J. M.: Migrating and nonmigrating semidiurnal tides in the upper atmosphere excited by tropospheric latent heat release, J. Geophys. Res., 108(A2), 1062, doi:10.1029/2002JA009466, 2003.

Hays, P. B., Wu, D. L., Burrage, M. D., Gell, D. A., Grassl, H. J., Lieberman, R. S., Marshall, A. R., Morton, Y. T., Ortland, D. A., and Skinner, W. R.: Observations of the diurnal tide from space,
J. Atmos. Sci., 51, 3077-3093, 1994.

Khattatov, B. V., Geller, M. A., Yudin, V. A., Hays, P. B., Skinner, W. R., Burrage, M. D., Franke, S. J., Fritts, D. C., Isler, J. R., Manson, A. H., Meek, C. E., McMurray, R., Singer, W., Hoffmann, P., and Vincent, R. A.: Dynamics of the mesosphere and lower thermosphere as seen by MF radars and the high-resolution Doppler imager/UARS, J. Geophys. Res., 101, 10393-10 404, 1996.

Kumar, V. S., Rao, P. B., and Krishnaiah, M.: Lidar measurements of stratosphere-mesosphere thermal structure at a low latitude: comparison with satellite data and models, J. Geophys. Res., 108, 4342, Doi:10.1029/2002JD003029, 2003.

Lu, W. T. and Fritts, D. C.: Spectral estimates of gravity wave energy and momentum fluxes, Part III: gravity wave-tidal interactions, J. Atmos. Sci., 50, 3714-3727, 1993.

Manson, A. H., Meek, C., Hagan, M. E., Hall, C., Hocking, W., MacDougall, J., Franke, S., Riggin, D., Fritts, D., Vincent, R., and Burrage, M.: Seasonal variations of the semi-diurnal and diurnal tides in the MLT: multi-year MF radar observations from 2 to $70^{\circ} \mathrm{N}$, and the GSWM tidal model, J. Atmos. Sol-Terr. Phys., 61, 809-828, 1999.

Manson, A. H., Luo, Y., and Meek, C.: Global distributions of diurnal and semi-diurnal tides: observations from HRDI-UARS of the MLT region, Ann. Geophys., 20, 1877-1890, 2002a.

Manson, A. H., Meek, C., Hagan, M. E., Koshyk, J., Franke, S., Fritts, D., Hall, C., Hocking, W., Igarashi, K., MacDougall, J., Riggin, D., and Vincent, R.: Seasonal variations of the semidiurnal and diurnal tides in the MLT: multi-year MF radar observations from $2-70^{\circ} \mathrm{N}$, modelled tides (GSWM, CMAM), Ann. Geophys., 20, 661-677, 2002b.

Manson, A. H., Meek, C. E., Hall, C. M., Nozawa, S., Mitchell, N. J., Pancheva, D., Singer, W., and Hoffmann, P.: Mesopause dynamics from the Scandinavian triangle of radars within the PSMOS-DATAR Project, Ann. Geophys., 22, 367-386, 2004, http://www.ann-geophys.net/22/367/2004/.

Mayr, H. G., Mengel, J. G., Talaat, E. R., Porter, H. S., and Chan, K. L.: Non-migrating diurnal tides generated with planetary waves in the Mesosphere, Geophys. Res. Lett., 30, 1832, doi:10.1029/2003GL017877, 2003.

McLandress, C., Rochon, Y., Shepherd, G. G., Solheim, B. H., Thuillier, G., and Vial, F.: The meridional wind component of the thermospheric tide observed by WINDII on UARS, Geophys. Res. Lett., 21, 2417-2420, 1994.

McLandress, C., Shepherd, G. G., and Solheim, B. H.: Satellite observations of thermospheric tides: results from the Wind Imaging Interferometer on UARS, J. Geophys. Res., 101, 4093-4114, 1996.

Miyahara, S. and Wu, D. H.: Effects of solar tides on the zonal mean circulation in the lower thermosphere: Solstice condition, J. Atmos. Terr. Phys., 51, 635-647, 1989.

Miyahara, S. and Forbes, J. M.: Interaction between gravity waves and the diurnal tide in the mesosphere and lower thermosphere, J. Meteorol. Soc. Jpn., 69, 523-531, 1991.

Miyahara, S., Portyagin, Y. I., Forbes, J. M., and Solovjeva, T. V.: Mean Zonal Acceleration and Heating of the 70- to 100-km region, J. Geophys. Res., 96, 1225-1238, 1991.

Miyahara, S., Yoshida, Y., and Miyoshi, Y.: Dynamical coupling between the lower and upper atmosphere by tides and gravity waves, J. Atmos. Terr. Phys., 55, 1039-1053, 1993. 
Miyahara, S. and Miyoshi, Y.: Migrating and non-migrating atmospheric tides simulated by a middle atmosphere general circulation model, Adv. Space Res., 20, 1201-1207, 1997.

Morton, Y. T., Lieberman, R. S., Hays, P. B., Ortland, D. A., Marshall, A. R., Wu, D., Skinner, W. R., Burrage, M. D., Gell, D. A., and Yee, J. H.: Global mesospheric tidal winds observed by the High Resolution Doppler Imager on board the Upper Atmosphere Research Satellite, Geophys. Res. Lett., 20, 1263-1266, 1993.

Namboothiri, S. P., Kishore, P., Murayama, Y., and Igarashi, K.: MF radar observations of terdiurnal tide in the mesosphere and lower thermosphere at Wakkanai $\left(45.4^{\circ} \mathrm{N}, 141.7^{\circ} \mathrm{E}\right)$, Japan, J. Atmos. Sol-Terr. Phys., 66, 241-250, 2004.

Oberheide, J., Hagan, M. E., Ward, W. E., Riese, M., and Offermann, D.: Modeling the diurnal tide for the Cryogenic Infrared Spectrometers and Telescopes for the Atmosphere (CRISTA) 1 time period, J. Geophys. Res., 105, 24 917-24 929, 2000.

Palo, S. E., Hagn, M. E., Meek, C. E., Vincent, R. A., Burrage, M. D., McLandress, C., Franke, S. J., Ward, W. E., Clark, R. R., Hoffmann, P., Johnson, R., Kurschner, D., Manson, A. H., Murphy, D., Nakamura, T., Protnyagin, Yu. I., Salah, J. E., Schminder, R., Singer, W., Tsuda, T., Virdi, T. S., and Zhou, Q.: An intercomparison between the GSWM, UARS, and ground based radar observations: a case-study in January 1993, Ann. Geophys., 15, 1123-1141, 1997,

http://www.ann-geophys.net/15/1123/1997/.

Pancheva, D., Mitchell, N. J., Hagan, M. E., Manson, A. H., Meek, C. E., Luo, Yi, Jacobi, Ch., Kürschner, D., Clark, R. R., Hocking, W. K., MacDougall, J., Jones, G. O. L., Vincent, R. A., Reid, I. M., Singer, W., Igarashi, K., Fraser, G. I., Nakamura, T., Tsuda, T., Portnyagin, Yu., Merzlyakov, E., Fahrutdinova, A. N., Stepanov, A. M., Poole, L. M. G., Malinga, S. B., Kashcheyev, B. L., Oleynikov, A. N., and Riggin, D. M.: Global-scale tidal structure in the mesosphere and lower thermosphere during the PSMOS campaign of June-August 1999 and comparisons with the global-scale wave model, J. Atmos. Sol-Terr. Phys., 64, 1011-1035, 2002.

Riggin, D. M., Meyer, C. K., Fritts, D. C., Jarvis, M. J., Murayama, Y., Singer, W., Vincent, R. A., and Murphy, D. J.: MF radar observations of seasonal variability of semidiurnal motions in the mesosphere at high northern and southern latitudes, J. Atmos. Sol-Terr. Phys., 65, 483-493, 2003.

She, C. Y., Sherman, J., Yuan, T., Williams, B. P., Arnold, K., Kawahara, T. D., Li, T., Xu, L. F., Vance, J. D., Acott, P., and Krueger, D. A.: The first 80-hour continuous lidar campaign for simultaneous observation of mesopause region temperature and wind, Geophys. Res. Lett., 30, 1319, doi:10.1029/2002GL016412, 2003.

Shepherd, M. and Fricke-Begemann, C.: Study of the tidal varia- tions in mesospheric temperature at low and mid latitudes from WINDII and potassium lidar observations, Ann. Geophys., 22, 1513-1528, 2004, http://www.ann-geophys.net/22/1513/2004/.

Smith, A. K.: Structure of the terdiurnal tide at $95 \mathrm{~km}$, Geophys. Res. Lett., 27, 177-180, 2000.

Smith, A. K.: Physics and chemistry of the mesopause region, J. Atmos. Sol-Terr. Phys., 66, 839-857, 2004.

States, R. J. and Gardner, C. S.: Thermal structure of the mesopause region $(80-105 \mathrm{~km})$ at $40^{\circ} \mathrm{N}$ latitude, Part II: diurnal variations, J. Atmos. Sci., 57, 78-92, 2000.

Teitelbaum, H., Vial, F., Mason, A. H., Giraldez, R., and Massebeuf, M.: Non-linear interaction between the diurnal and semidiurnal tides: terdiurnal and diurnal secondary waves, J. Atmos. Terr. Phys., 51, 627-634, 1989.

Vial, F.: Numerical simulations of atmospheric tides for solstice conditions, J. Geophys. Res., 91, 8955-8969, 1986.

Vincent, R. A., Tsuda, T., and Kato, S.: Asymmetries in mesospheric tidal structure, J. Atmos. Terr. Phys., 51, 609-616, 1989.

Vincent, R. A., Kovalam, S., Fritts, D. C., and Isler, J. R.: Longterm MF radar observations of solar tides in the low-latitude mesosphere: interannual variability and comparisons with the GSWM, J. Geophys. Res., 103, 8667-8683, 1998.

Williams, B. P. and She, C. Y.: Seasonal climatology of the nighttime tidal perturbation of temperature in the midlatitude mesopause region, Geophys. Res. Lett., 25, 3301-3304, 1998.

Wood, A. R. and Andrews, D. G.: A spectral model for simulation of tides in the middle atmosphere, III : results for the semidiurnal tide, J. Atmos. Sol-Terr. Phys., 59, 79-97, 1997.

Wu, Q., Killeen, T. L., Ortland, D. A., Solomon, S. C., Gablehouse, R. D., Johnson, R. M., Skinner, W. R., Niciejewski, R. J., and Franke, S. J.: TIMED Doppler interferometer (TIDI) observations of migrating diurnal and semidiurnal tides, J. Atmos. SolTerr. Phys., 68, 408-417, 2006.

Yi, F.: Short-term variability and temporary structures of tides and mean wind in the polar summer mesosphere, J. Atmos. Sol-Terr. Phys., 63, 749-757, 2001.

Zhang, S. D. and Yi, F.: A numerical study of nonlinear propagation of a gravity-wave-packet in compressible atmosphere, J. Geophys. Res., 104, D12, 14 261-14 270, 1999.

Zhang, S. D. and Yi, F.: A numerical study on global study on global propagations and amplitude growths of large scale gravity wave packets, J. Geophys. Res., 109, D07106, doi:10.1029/2003JD004429, 2004.

Zhang, S. D., Yi, F., and Hu, X.: MF radar observation of mean wind and tides of winter mesopause $(80-98 \mathrm{~km})$ region over Wuhan $\left(30^{\circ} \mathrm{N}, 114^{\circ} \mathrm{E}\right)$, J. Atmos. Sol-Terr. Phys., 66, 15-25, 2004. 